\title{
Raw Material Feeding and Its Influence on Operation Performance of Smelting Reduction Process with a Large Amount of Slag
}

\author{
Hiroyuki KATAYAMA, Takamasa OHNO, Masao YAMAUCHI, Takafumi KAWAMURA, ${ }^{1}$ Hiroshi \\ HIRATA $^{11}$ and Mitsitaka MATSUO ${ }^{1)}$
}

The Comittee for R \& D on New Iron-Ore Smelting Reduction of The Japan Iron and Steel Federation, Kudan-minami, Chiyoda-ku, Tokyo, 112 Japan.

Futtsu, Chiba-ken, 299-12 Japan.

1) Process Technology Research Laboratories, Nippon Steel Corporation, Shintomi,

(Received on August 11, 1992; accepted in final form on January 22, 1993)

\begin{abstract}
In order to know the necessary conditions of pretreatment of raw materials and feeding technologies, fine ore and highly volatile coal were supplied to the smelting reduction furnace directly, and the relation between feeding conditions and operation performance was investigated.

Fine materials were supplied by injection into the metal bath or by pouring with a small amount of carrier gas from above the slag layer. In injection, excessive stirring of bath causes the decrease of post combustion and the increase of iron dust generation. For fine ore, it is possible to supply by pouring with negligible carry-over, by keeping the specific surface area of a stream small.

When coal is supplied directly, volatile matter influences the post combustion, coal consumption and the amount of carry-over of carbon. It is possible to operate a smelting reduction furnace with direct addition of coal by suppressing carry-over, but pretreatment for decreasing coal consumption further was discussed.
\end{abstract}

KEY WORDS: smelting reduction; iron ore; coal; feeding; injection.

\section{Introduction}

One of the aims of research on the smelting reduction process is to produce iron with easily obtained and cheap raw materials, and with as least pretreatment as possible. That is, it is desirable to use fine ore without agglomeration. Also, regarding carbonanceous materials, it is ideal to use highly volatile coal directly in the smelting reduction furnace.

In this paper, the relationship between feeding technologies of raw materials and operation performance is investigated for the smelting reduction process. As feeding technologies of raw materials, injection and top addition of fine ore or fine coal, and top addition of lump coal were tested.

Experiments with a 100 ton smelting reduction furnace were performed by the $\mathrm{R} \& \mathrm{D}$ task force of the Committee for R \& D on New Iron-ore Smelting Reduction of the Japan Iron and Steel Federation. ${ }^{1)}$

\section{Concept of Smelting Reduction Process with a Thick Layer of Slag and Operation Performance}

The feature of the process is the combination of (i) a large amount of slag, (ii) soft blowing of oxygen from top and (iii) stirring of the bath by bottom bubbling. ${ }^{2)}$ Carbonaceous materials in the slag layer make it possible for a large amount of slag to exist stably in the furnance by suppressing vigorous slag foaming. ${ }^{3)}$ The thick layer of slag is necessary for separating an oxygen jet from a metal bath stirred by bottom bubbling. ${ }^{4)}$ Stirring of the bath is indispensable for accelerating reducing reaction and heat transfer. ${ }^{5}$ The aim of this process is to obtain effective performance, such as high post combustion without disturbing reducing reaction, high heat efficiency and suppression of dust generation.

The definitions of the main characteristics of operation are as follows:

Rate constant of iron ore reduction:

$$
\begin{aligned}
& K=\frac{(\text { Removed oxygen from iron ore) }}{(\% \mathrm{~T} . \mathrm{Fe})(\text { Cross area)(Time) }} \\
& \left(\mathrm{K} \text { mol- } \mathrm{O}_{2} /\left(\%, \mathrm{~m}^{2}, \min \right)\right)
\end{aligned}
$$

Post combustion:

$$
\begin{array}{r}
P C=\frac{\left\{\left(\% \mathrm{CO}_{2}\right)+\left(\% \mathrm{H}_{2} \mathrm{O}\right)\right\}}{\left(\% \mathrm{CO}_{2}\right)+(\% \mathrm{CO})+\left(\% \mathrm{H}_{2} \mathrm{O}\right)+\left(\% \mathrm{H}_{2}\right)} \\
\times 100(\%) \quad \ldots \ldots \ldots \ldots \ldots \ldots \ldots \ldots \ldots \ldots \ldots \ldots \ldots
\end{array}
$$

Heat efficiency of post combustion:

$$
\begin{array}{r}
\eta_{P C}=\left\{1-\frac{(\text { Superheat of exhaust gas })}{(\text { Heat generated by post combustion })}\right\} \\
\times 100(\%) \quad \ldots \ldots \ldots \ldots \ldots \ldots \ldots \ldots \ldots \ldots \ldots \ldots \ldots \ldots
\end{array}
$$

Iron dust generation:

$$
D_{\text {iron }}=\frac{(\text { Total iron in dust })}{(\text { Total iron in added ore })} \times 100(\%)
$$


Carbon dust generation:

$$
\begin{aligned}
D_{\text {carbon }}=\frac{(\text { Total carbon in dust })}{(\text { Total fixed carbon in added materials })} \\
\quad \times 100(\%)
\end{aligned}
$$

\section{Bottom Injection of Fine Materials}

\subsection{Experimental Method}

One of fine ore and fine coal was injected to metal bath in a 100 ton experimental furnace. ${ }^{6)}$ The composi- tion and size of fine materials are shown in Table 1. In order to inject fine materials, bottom bubbling gas was increased to about 5 times the standard amount for lump materials. Other operation conditions were almost the same as those for lump materials. ${ }^{6)}$

\subsection{Experimental Results and Discussion}

Figure 1 shows the relationship between the amount of bottom bubbling gas and various operation performance. When lump materials were used, the increase of metal droplets by bottom bubbling causes the decrease of post combustion and the increase of iron

\begin{tabular}{|c|c|c|c|c|c|c|c|}
\hline & \multicolumn{6}{|c|}{ Size $(\mathrm{mm})$} & \multirow{2}{*}{ Composition } \\
\hline & $>2.0$ & $2.0-1.0$ & $1.0-0.5$ & $0.5-0.25$ & $0.25-0.125$ & $\leqq 0.125$ & \\
\hline Ore & 30 & 30 & 2.2 & 4.1 & 10.8 & 79.9 & T. Fe: $68.0, \mathrm{SiO}_{2}: 0.96$ \\
\hline Coal & 8.4 & 35.5 & 22.7 & 16.4 & 7.5 & 11.3 & $\begin{array}{l}\text { F.C: } 52.6, \text { VM: } 35.4 \\
\text { Ash: } 12.0, \text { T.S: } 0.85\end{array}$ \\
\hline
\end{tabular}

Table 1. Composition and size distribution of fine materials for injection. (mass\%)
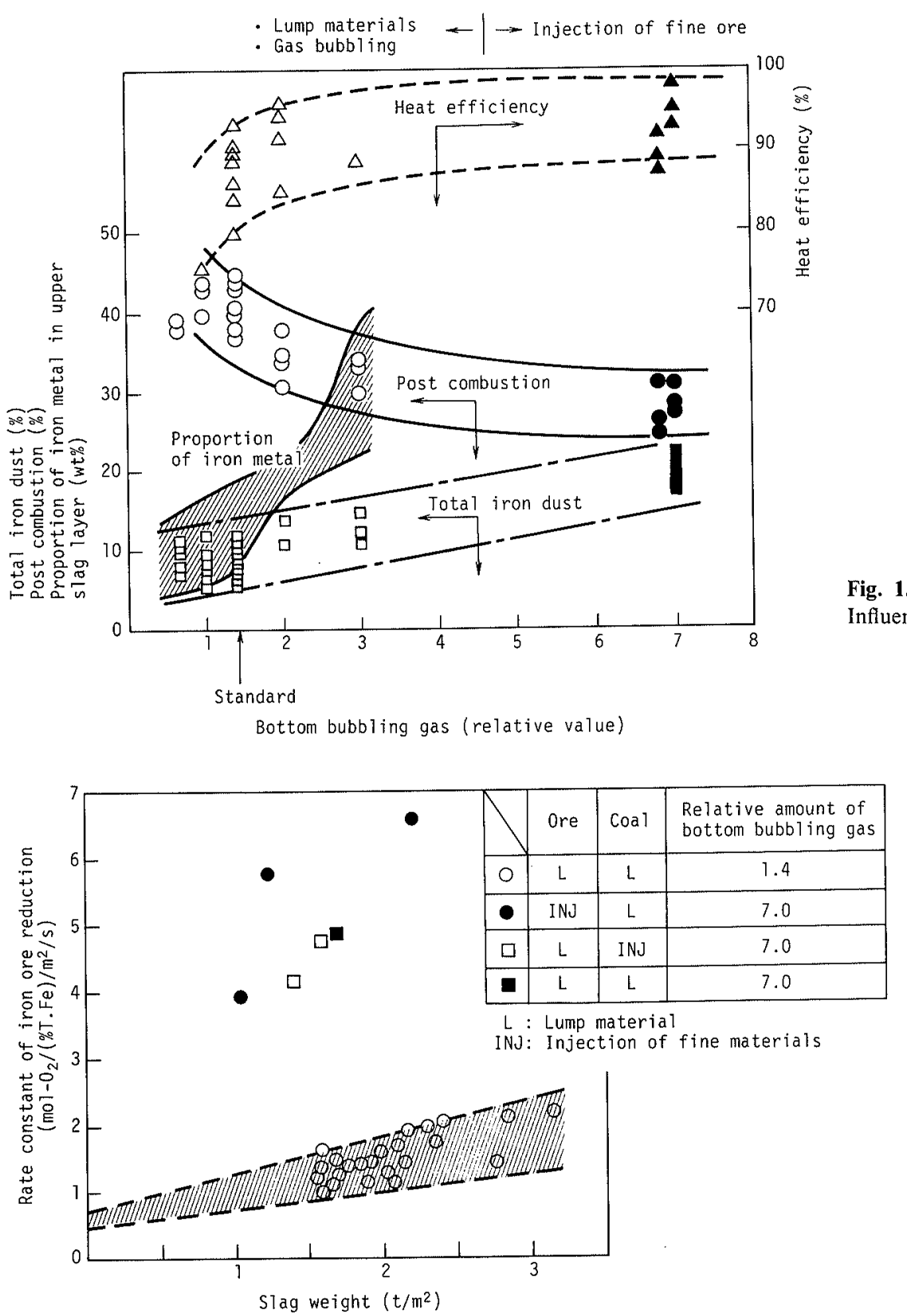

Fig. 1.

Infuence of bubbling intensity on operation performance.
Fig. 2.

Influence of various condition on rate constant of iron reduction. 
dust generation. ${ }^{2)}$ In bottom injection of fine ore, the trend was emphasized by increased amount of bubbling gas. In injection, metal droplets were ejected through a slag layer to combustion atmosphere.

Heat efficiency reaches saturation (about $90 \%$ ) at a relatively small amount of bubbling gas in this process. On the other hand, the rate constant of reduction increased 5 to 6 times by bottom injection, compared with standard bottom bubbling conditions (Fig. 2) and (T.Fe) was kept at a low level $(0.5-1.5 \%)$. But, when only the amount of bottom bubbling gas was increased (plots $\mathbf{\square}$ ), the increase of rate constant was almost same as in injection of fine ore.

The feeding rate of ore is limited by heat supply. By bottom injection, productivity decreases when oxygen flow rate is constant, because post combustion decreases at the same time. So, in this process, injection of fine ore is useful only within the tolerable amount of bubbling gas.

\section{Top Addition of Fine Materials}

In top addition of fine materials, there are two technolgies; injection through lance with high speed carrier gas, and 'pouring' with a small amount of carrier gas. The former has the virtue of injecting fine materials into molten slag, but there is the problem of pipe erosion when a large amount of materials must be injected. On the other hand, in the latter, engineering is easy if carry-over of fine materials can be suppressed by choosing conditions. Already, it is reported that carryover of fine chrome ore could be suppressed in a 5 ton converter. ${ }^{7)}$

Therefore, experiments with cold model and 100 ton smelting reduction furnace were performed, regarding the latter technology, for making clear if it could be applied to the charge of finer ore or fine carbonaceous material, and to larger furnances, in which the velocity of counter flow gas is higher.

\subsection{Experiment with Cold Model}

(1) Experimental Method

In the appratus shown in Fig. 3, air was blown horizontaly from 20 tuyeres installed to the lower part and uniform ascending gas current was produced in the upper part.

Fine materials were constantly supplied from a hopper through a nozzle and the amount of carry-over was measured. The conditions varied were as follows: fine materials (ore A (iron sand), ore B (pellet feed) and coke), feed rate of fine materials $(5-100 \mathrm{~g} / \mathrm{s})$, diameter of nozzle $(7,10,12 \mathrm{~mm} \phi)$ and ascending gas velocity $(2.3,3.7$, $5.1 \mathrm{~m} / \mathrm{s})$. Size distribution of fine materials is shown in Fig. 4. Plots show the theoretical amount of carry-over, which is calculated by considering the terminal velocity of a particle and ascending gas velocity. If each material acts as a particle, $55-80$ mass $\%$ of feed would be carried over, even the ascending gas velocity is $2.3 \mathrm{~m} / \mathrm{s}$, the lowest of test condition.

(2) Experimental Results and Discussion

The ratio of carry-over ((rate of carry-over/feed rate)

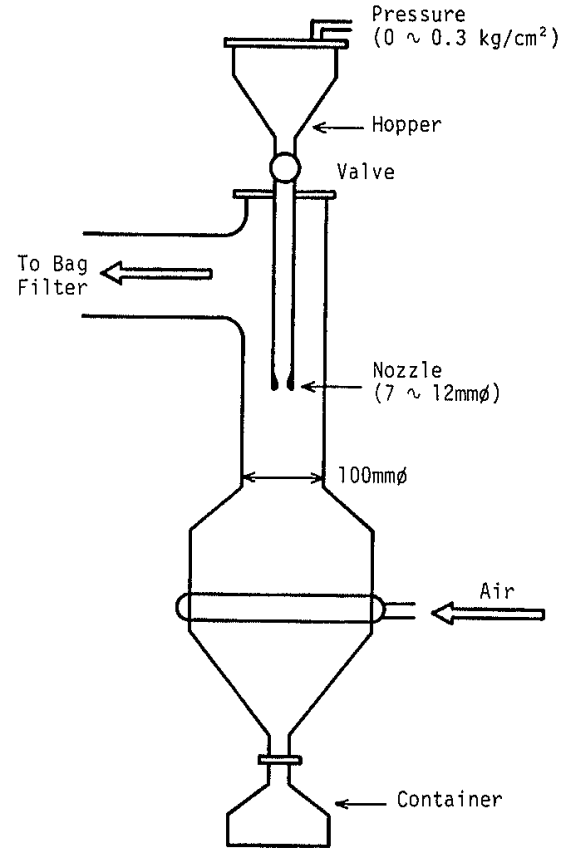

Fig. 3. Experimental apparatus.

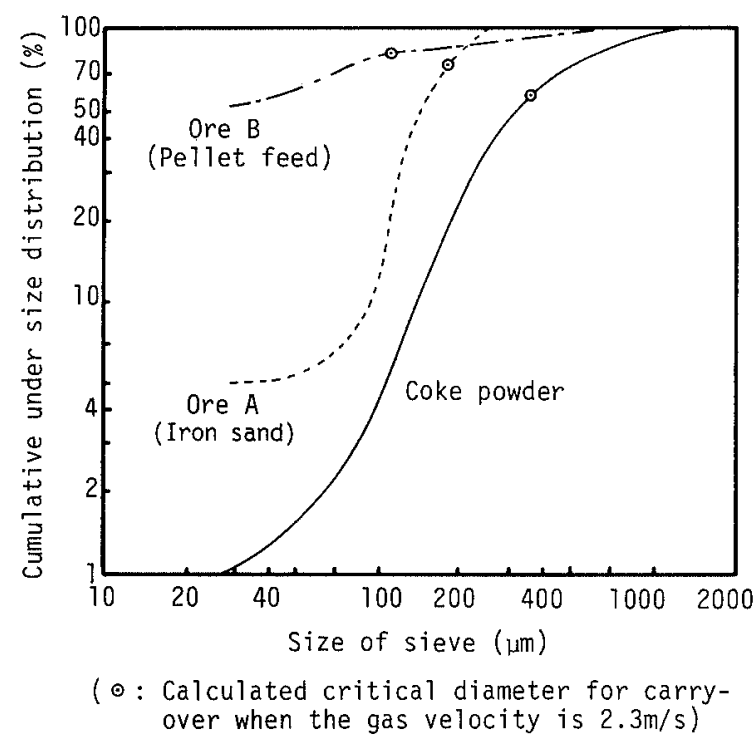

Fig. 4. Size distribution of fine materials used for experiment.

$\times 100 \%$ ) decreases drastically by increasing feed rate (Fig. 5). The influence of the kind of fine materials, size distribution and velocity of ascending gas current is not remarkable. The rate of carry-over $(\mathrm{g} / \mathrm{s})$ is nearly directly proportional to nozzle diameter, but the ratio of carry-over is inversely proportional to it (Fig. 6).

The stream of fine coke is shown in Fig. 7. When feed rate is small (b), the stream is unstable and disturbance is remarkable. On the other hand, the stream is stable above a critical feed rate and dispersion can be observed only at the surface of stream (a).

Therefore, the ratio of carry-over can be expressed approximately by Eq. $(6)^{8)}$

Ratio of carry-over $\propto \frac{\text { (Surface area of stream) }}{\text { (Feed rate) }}$

Increasing the length of stream will cause the spread 




Fig. 5. Relation between ratio of carry-over and feed rate.

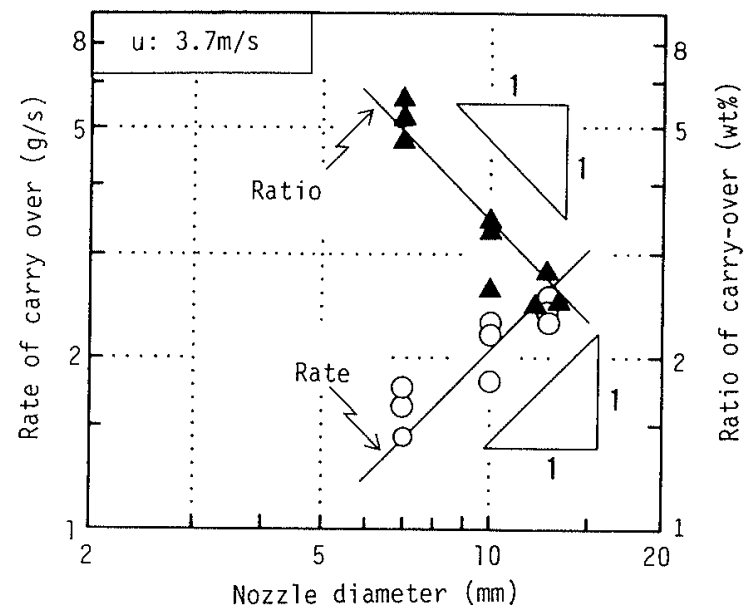

Fig. 6. Influence of nozzle diameter on carry-over (iron sand)

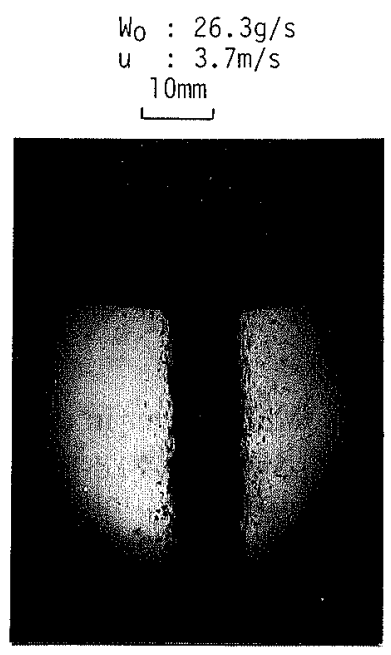

(a)

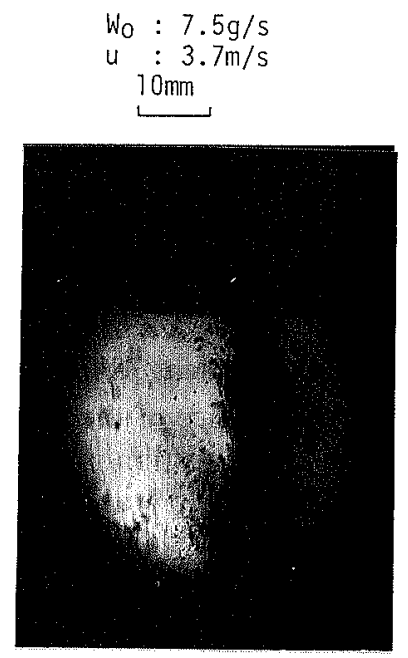

(b)
Fig. 7. View of stream of coke powder.

\section{of stream.}

In order to suppress the carry-over of fine materials, it is important to keep the specific surface area of the stream low by suppressing disturbance and by shortening the stream as much as possible.

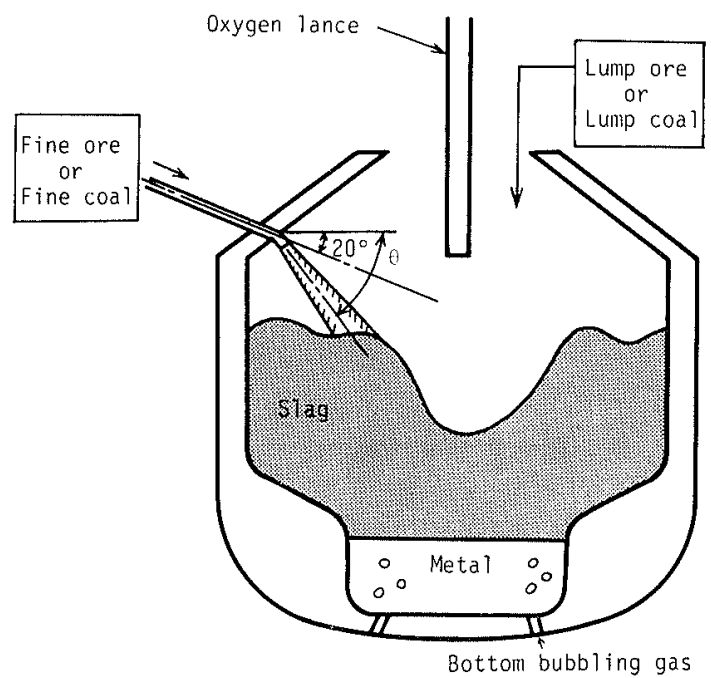

Fig. 8. Schematic drawing of pouring of fine materials into smelting reduction furnace.

Table 2. Size distribution of raw materials. (mass\%)

\begin{tabular}{lcrccc} 
& \multicolumn{5}{c}{ Size $(\mathrm{mm})$} \\
& $>5.0$ & $5.0-2.0$ & $2.0-1.0$ & $1.0-0.5$ & $\leqq 0.5$ \\
\hline Pellet feed ore & 0 & 8.0 & 8.8 & 4.9 & 83.3 \\
Sinter feed ore & 0 & 22.5 & 21.7 & 17.0 & 38.8 \\
Fine coal & 0 & 8.4 & 35.5 & 22.7 & 33.4 \\
Lump ore & 98.0 & 2.0 & 0 & 0 & 0 \\
\hline
\end{tabular}

\subsection{Experiment with 100 ton Smelting Reduction Furnace}

Fine materials were supplied using $\mathrm{N}_{2}$ gas through a hole in the shoulder of the furnace (Fig. 8). Varied conditions were the kind of fine materials (Table 2), nozzle angle, which is defined by the inclination of the nozzle tip from the horizontal plane ( $\theta$ in Fig. 8: $20^{\circ}$, $\left.50^{\circ}\right)$, and diameter of nozzle $(50 \mathrm{~mm} \phi, 80 \mathrm{~mm} \phi)$. The rate of fine material and carrier gas was constant for each material. The stream of fine materials was directed not to collide with the top blown oxygen jet.

The theoretical carry-over of fine materials, calculated by the same method as shown in Fig. 4, was found to be more than 50 mass $\%$ for sinter feed ore, more than 90 mass $\%$ for pellet feed ore and fine coal. The amount of carry-over was investigated by sampling the water of the wet dust catcher, weighting the precipitate and analyzing it.

Iron dust is generated, not only by carry-over of fine ore, but also by fuming and bubble bursting which are caused by contact of the oxygen jet and molten metal. As it is not easy to separate carry-over from total iron dust, the difference between iron dust generation with lump ore and with fine ore was assumed to be the amount of carry-over of fine ore.

\subsection{Experimental Results and Discussion}

In Fig. 9 total iron dust generated with fine ore is compared with that with lump ore. The reason why total iron dust depends on the amount of slag is that the contact of oxygen jet and molten metal (i.e., metal bath 


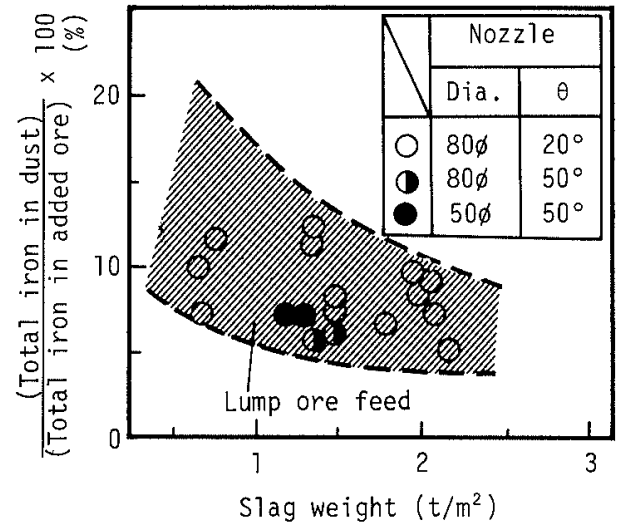

(a) sinter feed ore

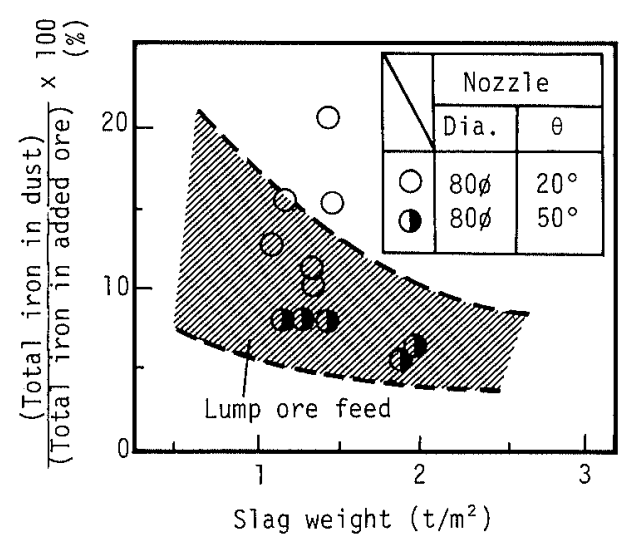

(b) Pellet feed ore

Fig. 9. Comparison of fine ore addition with lump ore addition. (Ore feed rate; $37-42 \mathrm{t} / \mathrm{h}$ )

and metal droplets in the slag layer) decreases with increase of slag. ${ }^{2)}$ In the case of sinter feed ore (a), no difference is observed between iron dust generation with lump ore and with fine ore. It means that the amount of carry-over of fine ore is negligible. The influence of nozzle diameter, that is, gas velocity is not remarkable. Though the amount of total iron dust is rather high, its decrease was discussed in another paper ${ }^{2)}$ from the standpoint of decreasing the contact of oxygen jet and molten metal.

On the other hand, in the case of finer pellet feed ore, the amount of total iron dust is higher than that with lump are, when nozzle angle is $20^{\circ}$ (plots $\bigcirc$ in Fig. 9 (b). With the change of the nozzle angle to $50^{\circ}$ (plots ()), the total iron dust decreases to the same range as with lump ore. This seems to be caused by shortening the stream of fine ore to the molten slag layer. These results mean that it is possible to supply fine ore from the top by pouring, with negligible carry-over, independent of size of fine ore.

On the other hand, when fine coal was supplied under the same condition as fine ore, the carbon dust generation was high $(30-45 \%), 1 / 2$ or $1 / 3$ of theoretical carry-over became dust. As the difference between carry-over of iron ore and that of coke is small in the cold model experiment, the phenomenon after reaching the slag layer seems to be different for ore and for carbonaceous materials. That is, iron ore can be captured by molten slag, because it is wettable to slag, but, as carbonaceous materials is less
Table 3. Composition of carbonaceous materials. (mass \%)

\begin{tabular}{lccccccccc}
\hline & \multicolumn{3}{c}{ Ultimate analysis (dry) } & & \multicolumn{4}{c}{ Proximate analysis } \\
\cline { 2 - 3 } \cline { 7 - 9 } & C & H & O & & VM & Ash & F.C & Moisture \\
\hline HVM coal & 75.2 & 5.08 & 8.34 & & 36.8 & 8.5 & 51.1 & 3.6 \\
MVM coal & 78.9 & 3.56 & 5.84 & & 25.8 & 9.6 & 61.2 & 3.4 \\
Coke & 87.5 & - & - & & - & 12.1 & 84.9 & 3.0 \\
\hline
\end{tabular}

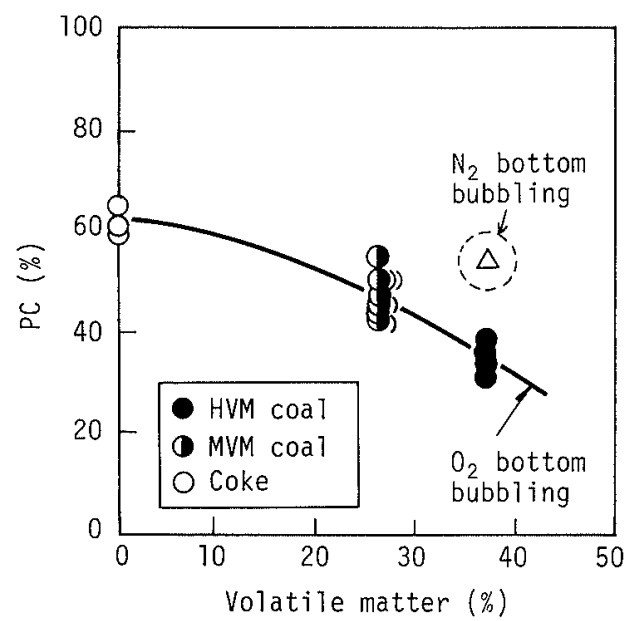

Fig. 10. Relation between volatile matter and post-combustion ratio ( 5 ton furnace). (Stirring intensity by bottom bubbling: $2.5-3.5 \mathrm{~kW} / \mathrm{t}$, top blowing of oxygen: $900 \mathrm{Nm}^{3} / \mathrm{h}$, oxygen blowing nozzle: $8.9 \mathrm{~mm} \phi \times 7$ holes, temperature of metal bath: $1480 \pm 30^{\circ} \mathrm{C}$ )

wettable to slag, it has the possibility to be carried over as long as it exists in the smelting reduction furnace.

\section{Direct Use of Coal in Smelting Reduction Furnace}

\subsection{Experimental Method}

The influence of volatile matter on operation performance must be paid attention to, in the direct use of coal in the smelting reduction process.

In 5 and 100 ton experimental smelting reduction furnaces, various carbonaceous materials (Table 3) were tested. Each carbonaceous material was supplied continuously from the top of the furnace.

\subsection{Experiment Results}

The influence of the content of volatile matter in coal on post combustion is shown in Fig. 10. The oxygen jet blown from top was controlled not to invade into the lower $30 \%$ of slag layer. Post combusion is decreased by the increase of volatile matter under the same conditions of oxygen blowing. When bottom blowing gas was changed from $\mathrm{O}_{2}$ containing gas to $\mathrm{N}_{2}$ gas, post combustion was increased by about $10 \%$. Increasing post combustion itself is not impossible by controlling top blowing or bottom bubbling conditions.

The relation between post consumption and coal consumption for various types of carbonaceous materials is shown in Fig. 11. Below the critical post combustion, coal consumption decreases with increasing post combustion, and coal consumption agrees with that calculated by the heat balance on the assumption that 


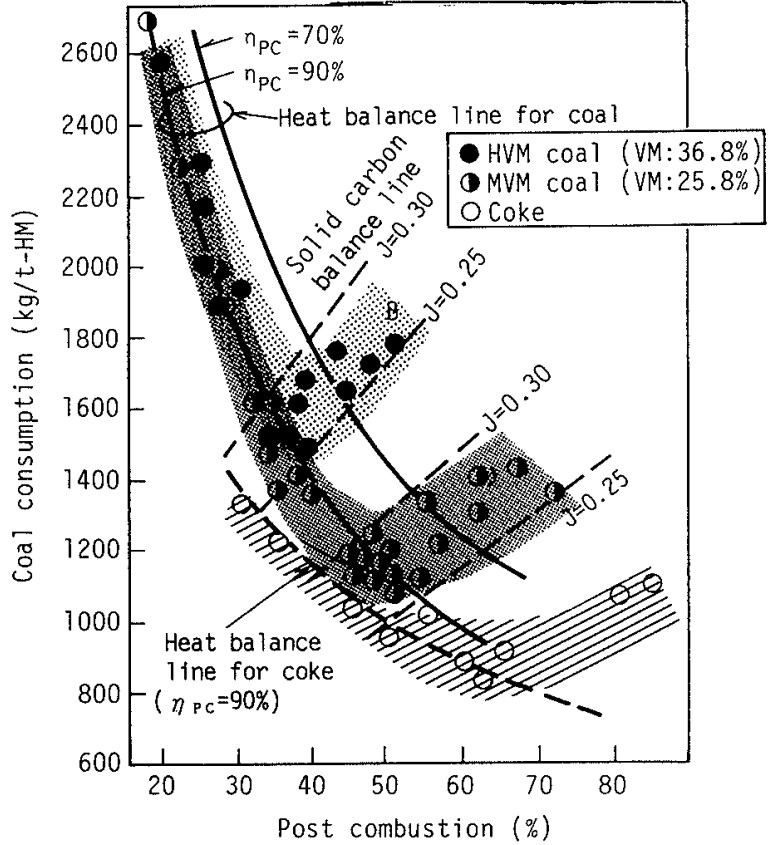

Fig. 11. Relation between post combustion and consumption for various type of materials ( 5 ton furnace). (Top blowing of oxgen: $900 \mathrm{Nm}^{3} / \mathrm{h}$, oxygen blowing nozzle: $8.9 \mathrm{~mm} \phi \times 7$ holes, bottom blowing of oxygen: $30 \mathrm{Nm}^{3} / \mathrm{h}$, temperature of metal bath: $1480 \pm$ $30^{\circ} \mathrm{C}$ )

Size distribution before supply

\begin{tabular}{|c|c|c|c|}
\hline & $>10 \mathrm{~mm}$ & $10 \sim 2 \mathrm{~mm}$ & $\leqq 2 \mathrm{~mm}$ \\
\hline Coal & 75 & 18 & 7 \\
\hline Coke & 75 & 16 & 9 \\
\hline
\end{tabular}

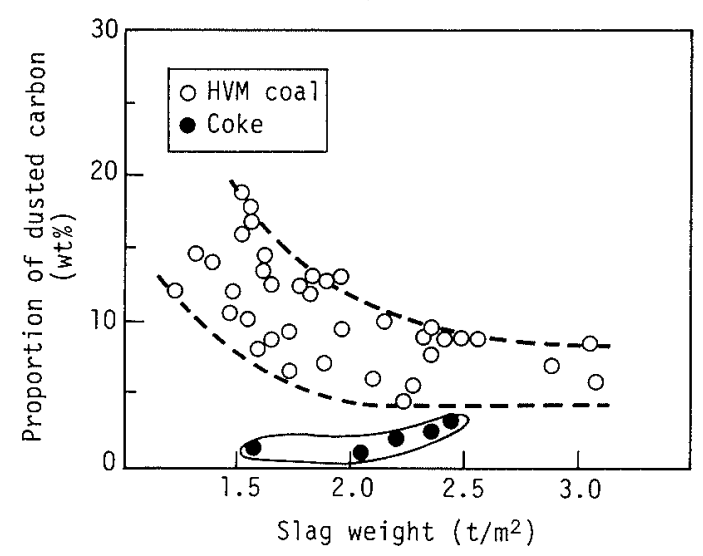

Fig. 12. Influence of the type of carbonaceous material on the carbon dust generation (100 ton furnance).

heat efficiency is about $90 \%$. But, over the critical post combustion, coal consumption does not decrease with increasing post combustion. The critical post combustion decreases with the increasing the content of volatile matter in coal.

Figure 12 shows the influence of various conditions on carbon dust generation. Carbon dust generation is decreased by increasing the amount of slag in operation using HVM coal. The difference between carbon dust generation with coke and with coal is remarkable, though their size distributions were almost the same before supply to the smelting reduction furnace.

\subsection{Discussion}

(1) Influence of solid carbon on coal consumption

The reason why the coal consumption does not decrease beyond the critical post consumption is explained by the concept of the necessary amount of solid carbon. ${ }^{97}$ Solid carbon in coal added in the smelting reduction furnace is consumed as follows;

(i) for reduction of iron oxide in slag,

(ii) for carburization of metal,

(iii) by burning by oxidizing atmosphere, and for reduction or carburization of reoxidized or decarburized metal by oxidizing atmospher.

As the presence of solid carbon in slag is necessary for stable operation without vigorous slag foaming, ${ }^{3)}$ it is necessary to supply solid carbon consumed by (i)-(iii).

The item (iii), i.e., the amount of burned solid carbon, can be calculated by taking solid carbon balance. And by assuming that the amount of burned solid carbon is proportional to the amount of oxygen gas blown, $J$ value is defined by Eq. (7) as a characteristic of the operation on the burning of carbonaceous materials..$^{9 j}$

$J=\frac{\text { Burned solid carbon }}{\mathrm{O}_{2} \text { gas blown from top lance }}\left(\mathrm{kg}-\mathrm{C} / \mathrm{Nm}^{3}-\mathrm{O}_{2}\right)$

The amount of solid carbon, which is defined as residual carbon after heating, depends on heating conditions. When coal is rapidly heated, the amount of volatile matter is higher than the analytical value by $5-20 \%$ depending on the type of coal. ${ }^{10)}$ If the value is assumed to be $10 \%$, the amount of solid carbon in coal: $\langle\mathrm{FC}\rangle$ is expressed by Eq. (8).

$$
\langle\mathrm{FC}\rangle=[\mathrm{FC}]-[\mathrm{VM}] \times 0.1
$$

where, $[\mathrm{FC}]$ : analytical value of fixed carbon $(\%)$,

$[\mathrm{VM}]$ : analytical value of volatile matter $(\%)$.

$J$ value obtained in the experiments with nonpretreated materials was between 0.25 and $0.30 \mathrm{~kg}-\mathrm{C} /$ $\mathrm{Nm}^{3}-\mathrm{O}_{2}$. The amount of carbonaceous materials necessary for supplying the consumed solid carbon: $G_{\text {coal }}$ can be expressed by Eq. (9).

$G_{\text {coal }}=$ [(Amount of solid carbon for reduction and carburization $)+($ Top blown oxygen $) \times J+$ (Amount of decarburization by bottom blowing gas $)] /(\langle\mathrm{FC} \%\rangle / 100)$

$$
\begin{gathered}
=\left\{\frac{3.22[\mathrm{Fe} \%][100-(\mathrm{PR} \%)]+1000[\mathrm{C} \%]}{1.12(1-r) \cdot J+1.2 r}\right. \\
-833[\mathrm{C} \%]\left[1+\frac{(\mathrm{PC} \%)}{100}\right] \\
\quad-2.69[\mathrm{Fe} \%][100-(\mathrm{PR} \%)]\} \mid \\
\left\{\frac{\langle\mathrm{FC} \%\rangle}{1.12(1-r) \cdot J+1.2 r}+0.625\langle\mathrm{O} \%\rangle\right. \\
\left.-0.833\langle\mathrm{C} \%\rangle\left[1+\frac{(\mathrm{PC} \%)}{100}\right]-0.05\langle\mathrm{H} \%\rangle(\mathrm{PC} \%)\right\}
\end{gathered}
$$




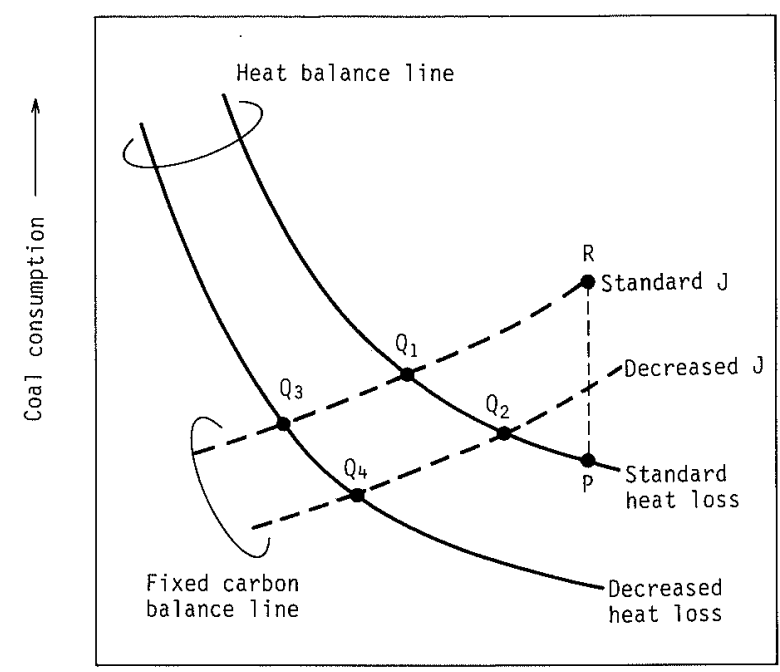

Post combustion $\longrightarrow$

Fig. 13. Schematic drawing of influence of $J$ value and heat loss on coal consumption in smelting reduction with high volatile matter coal. ( $\eta_{\mathrm{PC}}$ and materials' conditions are constant.)

where, $(\mathrm{PR} \%)$ : ratio of prereduction of ore

$r$ : proportion of bottom blowing of oxygen $(-)$

$[X \%]$ : composition of $X$ element in metal (mass \%)

$\langle X \%\rangle$ : composition of $X$ element in coal (dry base) (mass \%).

The calculated results with $J$ value of 0.25 and $0.30 \mathrm{~kg}-\mathrm{C} / \mathrm{Nm}^{3}-\mathrm{O}_{2}$, are shown as dotted lines in Fig. $11 .{ }^{9)}$ These lines agree with the relation between post combustion and coal consumption beyond the critical post combustion. This means that coal consumption beyond the critical post combustion is determined not by the heat balance but by the necessary amount of solid carbon.

In Fig. 13, the influence of operation condition on post combustion and coal consumption is schematically shown, by the concept of necessary amount of solid carbon. The conditions of supplied materials are constant. It is possible to operate at point $\mathrm{P}$ temporarily, but, if heat efficiency is kept at same value, solid carbon remaining in the slag layer decreases gradually and finally vigorous slag foaming occurs. If the amount of carbonaceous materials supplied is increased, the operational point moves from $P$ to $Q_{1}$. Of course, if heat is not used effectively for reduction of iron oxide, the operational point moves from $\mathrm{P}$ to $\mathrm{R}$. Therefore, the stable operation point for minimizing coal consumption is $Q_{1}$, that is, the cross point of heat balance line and the line determined by the necessary solid carbon, for standard value of $J$.

As the $J$ value is a technical characteristic on the combustion of solid carbon in the smelting reduction furnace, it may be possible to be decreased to some extent by controlling the operational conditions. For example, as water contained in raw materials accelerates the oxidation of solid carbon, drying of raw materials is useful for decreasing $J$ values. ${ }^{11)}$ The stable operation



Fig. 14. Influence of heating temperature and the initial size of high VM coal on the formation small size char and remaining volatile matter in a simulation test.

point moves to $\mathrm{Q}_{2}$ by decreasing $J$ value, and post combustion increases and coal consumption decreases.

When heat loss is decreased by scaling up of furnace, heat balance line shifts downward. Then, the stable operation point is $\mathrm{Q}_{3}$ at standard $J$ value, and post combustion is decreased. If $J$ value is decreased at the same time, the stable operation point is $\mathrm{Q}_{4}$, and the decrease of necessary heat can be effectively combined with the decrease of coal consumption.

(2) Influence of Heating Condition of Coal on Fragmentation

Coal fragmentation in a smelting reduction furnace was simulated by following method. ${ }^{12)}$ Lump coal of various sizes was heated on molten pig iron of $1350^{\circ} \mathrm{C}$. Also, lump coal was heated in a mini-rotary furnace, in which the temperature was kept at each temperature between 100 and $1000^{\circ} \mathrm{C}$, for $1 \mathrm{~h}$. Coal char obtained was unbound in drum tester $(700 \mathrm{~mm} \phi \times 510 \mathrm{~mm}, 1$ fin of $90 \mathrm{~mm}$ high) and cumulative undersize of $4 \mathrm{~mm}$ was measured, because the particles of less than about $4 \mathrm{~mm} \phi$ are theoretically carried-over in the smelting reduction furnace, being considered the oxidation in the furnace and counter current of gas.

Figure 14 shows the influence of initial size of coal and heating temperature on the amount of cumulative undersize of $4 \mathrm{~mm} \phi$. The generation of undersize was remarkable when heating temperature was about $400^{\circ} \mathrm{C}$ and higher than $1000^{\circ} \mathrm{C}$ and rather low when heating was between $800-900^{\circ} \mathrm{C}$. In these experiments, heating speed is related to heating temperature. Therefore, it seems to be caused by the phenomena that the structure of coal char becomes coarse when heating speed of coal is higher, but the microstrength of the matrix increases with heating temperature. The influence of initial size of coal on the generation of undersize of $4 \mathrm{~mm} \phi$ was not remarkable when heating temperature was above $800^{\circ} \mathrm{C}$. 


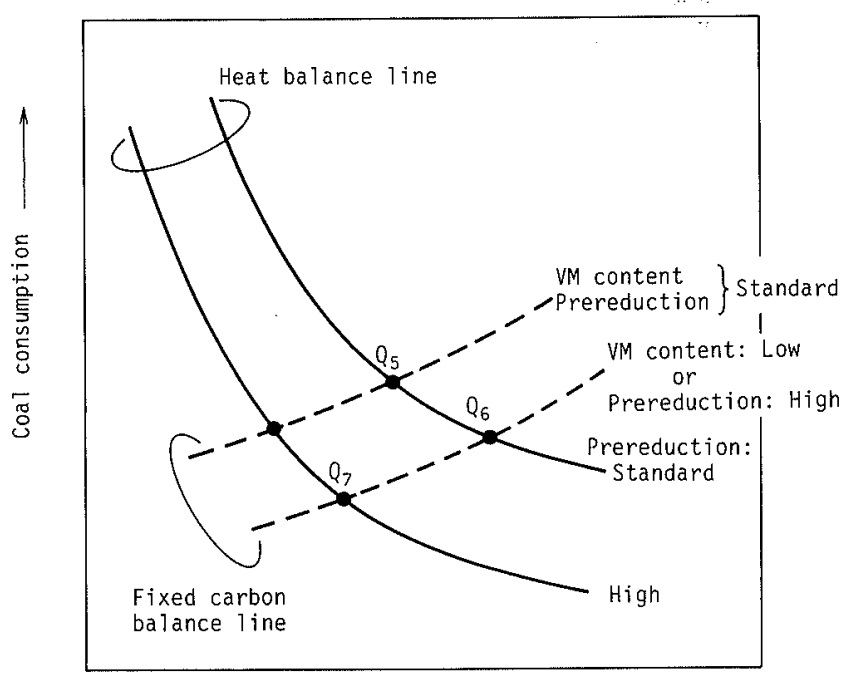

Post combustion

Fig. 15. Schematic drawing of influence of materials' conditions on coal consumption in smelting reduction with high volatile matter coal. ( $J$ value, $\eta_{\mathrm{PC}}$ and heat loss are constant.)

Based on this result, high volatile coal, which was pretreated by heating to $850^{\circ} \mathrm{C}$ in a rotary kiln, was supplied to 5 ton smelting reduction furnace. The amount of carbon dust generation was almost the same as that when metallurgical coke was used. ${ }^{12)}$

\section{Feeding Technologies and Total Process of Smelting Reduction}

Fine ore can be supplied into a smelting reduction furnace without agglomeration by pouring. Therefore, it is possible to combine smelting reduction furnace with, for example, a fluidized bed for drying and prereducing fine ore. Both of heat balance line and the line determined by the necessary solid carbon shifts downward with increase of prereduction of ore, and minimum coal consumption decreases (point $Q_{7}$ in Fig. 15).

When lump coal is supplied directly to the smelting reduction furnace, fragmentation of char occurs. Though it is not impossible to operate the smelting reduction furnace with small size char decrease of carry-over of char is desirable. For suppressing carry-over of char, the following two technologies are reported;

1) To increase the amount of slag and protect char from ascending gas current. ${ }^{2)}$

2) To decrease the speed of ascending gas current by pressurizing. ${ }^{13)}$

But, for more effective operation (e.g. with lower consumption of coal and oxygen gas), the content of volatile matter is desirably lowered as much as possible when carbonaceous material is supplied into smelting reduction furnace (point $Q_{6}$ in Fig. 15).

As one method of pretreatment of ore and coal, heating them in a furnace for utilizing volatile matter for prereduction of ore is reported. ${ }^{14-16)}$ If it is possible to decrease remove volatile matter of carbonaceous material and to prereduce ore at the same time, it is desirable for decreasing consumption of coal and oxygen gas and for increasing productivity.

\section{Summary}

Experiments on various technologies for feeding raw materials into the smelting reduction furnace with a large amount of slag were performed, and the relation between feeding technologies and operational performance was discussed.

(1) When bottom bubbling is excessive in injection of fine materials into the metal bath, problems such as decrease of post combustion and increase of iron dust generation occur. So, injection of fine materials is useful within the tolerable amount of bubbling gas.

(2) The feeding technology of fine ore by pouring with a small amount of carrier gas was tested by cold model. Independent of the kind and size of fine materials, the amount of carry-over can be decreased to a negligible level, by keeping the specific surface area of the stream of fine materials low. In the smelting reduction furnace, the amount of carry-over was negligible for fine ore, but about ten times as high for fine coal. The difference in carry-over of carbonaceous materials seems to be caused by the wettability of fine materials to molten slag.

(3) When various kinds of carbonaceous materials were supplied into smelting reduction furnace, coal consumption did not decrease with the increasing post combustion beyond the critical post combustion. The critical post combustion decreases with increasing content of volatile matter of coal. The minimum coal consumption is determined as the cross point of heat balance line and the line determined by the necessary amount of solid carbon. The minimum coal consumption decreases with the increase of the prereduction of ore and with the decrease of the content of volatile matter in carbonaceous materials supplied to smelting reduction furnace.

(4) When coal is supplied directly to the smelting reduction furnace, the carry-over of carbon is higher than when coke is used. It is caused by the fragmentation of coal in rapid heating. When coal is heated at $800-900^{\circ} \mathrm{C}$ in mini-rotary furnace, the fragmentation of coal char was suppressed, and when the char, which was heated to $850^{\circ} \mathrm{C}$ by rotary kiln, was used in 5 ton smelting reduction furnace, the carry-over of carbon was the same level as with coke.

(5) The combination of smelting reduction furnace with prereduction of fine ore, by e.g. fluidized bed, is possible, because fine ore can be supplied by pouring without agglomeration. Though direct use of coal is possible by suppressing carry-over of carbon, pretreatment for decreasing coal consumption further was discussed.

\section{REFERENCES}

1) T. Inatani: Ironmaking Conf. Proc., 50 (1991), 651.

2) H. Katayama, T. Ibaraki, T. Ohono, M. Yamauchi, H. Hirata and $\mathrm{T}$. Inomoto: ISIJ Int., to be published.

3) Y. Ogawa, H. Katayama, H. Hirata and N. Tokumitsu: ISIJ Int., 32 (1992), 87.

4) M. Fujita, H. Katayama, K. Kuwahara, C. Saito, H. Ishikawa and H. Kajioka: Tetsu-to-Hagané, 74 (1988), 680.

5) H. Katayama, T. Ohono, M. Yamauchi, M. Matsuo, T. Kawamura and T. Ibaraki: ISIJ Int., 32 (1992), 95. 
6) M. Yamauchi, T. Ibaraki, M. Kanemoto, M. Matsuo, H. Hirata and T. Inatani: CAMP-ISIJ, 3 (1990), No. 4, 1073.

7) H. Katayama, M. Kuwahara, H. Hirata, J. Yagi, C. Saito, and M. Fujita: Tetsu-to-Hagané, 76 (1990), 1855.

8) H. Katayama, M. Kuwahara, T. Ohono, M. Yamauchi and H. Hirata: Tetsu-to-Hagané, 78 (1992), 544.

9) M. Matsuo, C. Saito, H. Katayama, H. Hirata and Y. Ogawa: Tetsu-to-Hagané, 76 (1990), 1879.

10) T. Kawamura and H. Ishikawa: Tetsu-to-Hagané, 78 (1992), 360.

11) Y. Sakamoto, T. Ibaraki, M. Yamauchi, M. Kanemoto, M.
Matsuo and H. Katayama: CAMP-ISIJ, 5 (1992), No. 4, to be published.

12) H. Katayama, T. Kawamura, H. Hirata, T. Ohno, K. Kobayashi and M. Yamauchi: Tetsu-to-Hagané, 78 (1992), to be published.

13) K. Takahashi, H. Tanabe, K. Iwasaki, M. Moriya, I. Kikuchi and M. Kawakami: Tetsu-to-Hagané, 76 (1990), 1887.

14) W. K. Lu, C. Bryk and H. Y. Gou; Proc. 6th Process Tech. Conf., Vol. 6, (1986), 1065.

15) K. Kuwahara and C. Saito: CAMP-ISIJ, 2 (1989), No. 1, 120.

16) T. Usui, Z. Morita, T. Watanabe and T. Yokoyama: CAMP-ISIJ, 4 (1991), No. 1, 33. 